\title{
Geōchemical

\section{Forty-year pollution history of microplastics in the largest marginal sea of the western Pacific}

\author{
M. Chen ${ }^{1,2}$, M. Du ${ }^{2 *}$, A. Jin ${ }^{1}$, S. Chen ${ }^{2}$, S. Dasgupta ${ }^{2}$ \\ J. $\mathrm{Li}^{2}, \mathrm{H} . \mathrm{Xu}^{2}, \mathrm{~K} . \mathrm{Ta}^{2}, \mathrm{X}$. Peng $^{2 *}$
}

OPEN ACCESS

Abstract

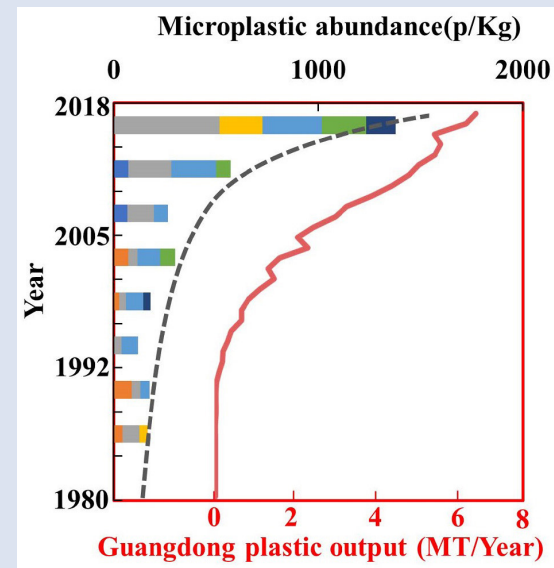

Marine sediments have been considered to be a major sink for microplastics, yet the pollution history of microplastics recorded in these sediments remains poorly understood. Using a combination of ${ }^{210} \mathrm{~Pb}$ chronology and quantification of microplastics in undisturbed sediment cores, here we established the forty-year pollution history of microplastics in the northern South China Sea (SCS), the largest marginal sea of the western Pacific. We found that the pollution of microplastics in the northern SCS commenced in the 1980s. A dramatic increase of microplastic abundance in about 1998 marked an important breakpoint for microplastic contamination. Since then, microplastic abundances in the sediments have continued to increase and reached the highest level in 2018. This was well in line with the increasing trend of plastic output in the local industries. Reconstructing regional pollution history further revealed the shift of microplastic depocentres in the northern SCS over the past forty years. We estimated that the microplastic abundances in the sediments at nearshore stations will double by 2028 . Our results provide the first example of the reconstruction of microplastic pollution history in marine sediments and new insights into how microplastics contaminated the marginal sea.

Received 29 November 2019 | Accepted 6 March 2020 | Published 3 April 2020

\section{Letter}

Plastics are widely used today because they are unmatched by any competing materials used in packaging or construction (Andrady and Neal, 2009). The global annual production of plastics rapidly increased from about 2 million tonnes (MT) in 1950 to 420 MT in 2017 (Geyer et al., 2017; Plastics Europe, 2018). It is estimated that plastic waste could increase to 155-265 MT per year by 2060, the majority of which would eventually enter the ocean (Lebreton and Andrady, 2019). Plastic debris has been reported from the sea surface, water column, seabed and marine biota (Galgani et al., 1996; Kukulka et al., 2012; Law et al., 2010; Goldstein et al., 2012; Gall and Thomson, 2015). Under the influence of light, mechanical abrasion, waves, temperature fluctuations, and possible biodegradation, plastics fragment into smaller particles with sizes less than $5 \mathrm{~mm}$, termed as microplastic (Singh and Sharma, 2008; Arthur et al., 2009). Most microplastics may eventually sink into the seafloor (Thompson et al., 2004; Claessens et al., 2011; Woodall et al., 2014; Bergmann et al., 2017; Peng et al., 2018) and accumulate over time in the sedimentary sequence (Matsuguma et al., 2017; Martin et al., 2017). Yet, the pollution history of microplastics documented in these sediments is still poorly understood. So far little is known about when and how microplastics accumulated in marine sediments in the past, creating a hiatus in the evaluation, prevention, and control of plastic pollutions.

The South China Sea (SCS) is the largest marginal sea of the western Pacific where active land-sea interaction exists. The continental shelf of the northern SCS with a water depth of less than $500 \mathrm{~m}$ is the convergence point of several big rivers in south China, such as Xijiang, Dongjiang, Zhujiang, Hanjiang, Moyangiiang, and Jianjiang. The first four fall within the twenty most polluting rivers, as predicted by the global river plastic input model (Lebreton et al., 2017). The Xisha Trough of the northern SCS extends east-west and deepens eastwards from 1500 to $3400 \mathrm{~m}$ (Qiu et al., 2001). In the western flank of the trough, there is a series of 19 tributary submarine canyons named Xisha Canyon. All the submarine canyons in the northern SCS slope extend from NE- and NW-trending directions (Hui et al., 2019). Large plastics dumps were found to occur in these submarine canyons (Peng et al., 2019). However, the distribution, source, migration, and pollution history of microplastics in the sediments of the northern SCS are still poorly understood.

\footnotetext{
1. Ocean College, Zhejiang University, Zhoushan, Zhejiang 316021, China

2. Institute of Deep-Sea Science and Engineering, Chinese Academy of Sciences, Sanya, Hainan 572000, China
}

Corresponding author (email: xtpeng@idsse.ac.cn; mdu@idsse.ac.cn) 


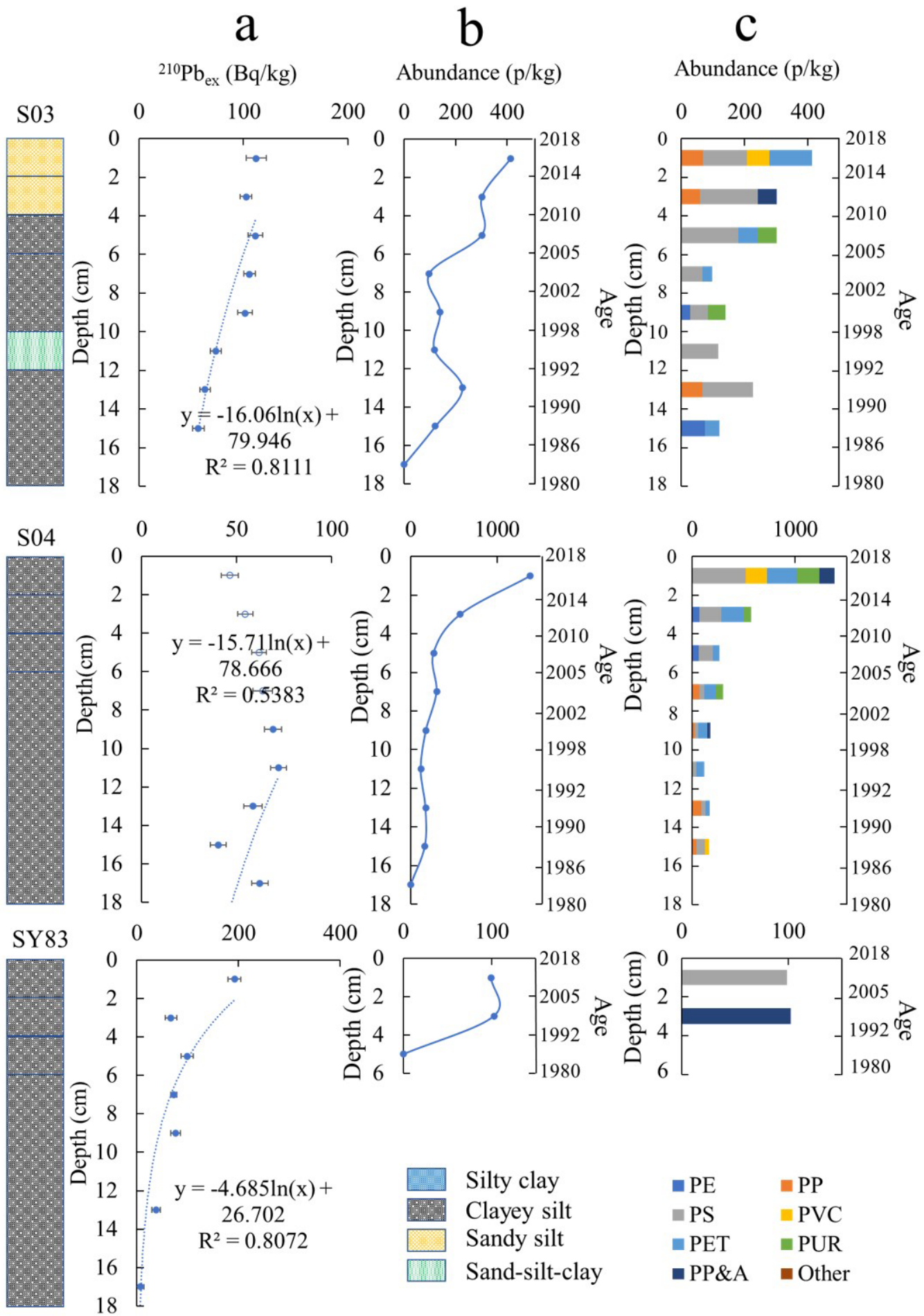

Figure 1 The profiles of excess ${ }^{210} \mathrm{~Pb}$, microplastic abundance and microplastic composition of sediment cores at $\mathrm{S} 03$, S04, and SY83 stations (the profiles of sediment cores at SY81, SY87, and SQW43 stations are shown in Fig. S-1). (a) Excess ${ }^{210} \mathrm{~Pb}$ profile. The sediment rates were calculated according to the gradient of the excess ${ }^{210} \mathrm{~Pb}$ as a function of the depth. (b) Microplastic abundance (pieces per kg dry weight). (c) Microplastic composition. PE-polyethylene, PP-polypropylene, PS-polystyrene, PVC-polyvinyl chloride, PET-polyethylene terephthalate, PUR-polyurethane, PP\&A includes polyester, polyamide, rayon and acrylic.

${ }^{210} \mathrm{~Pb}$ dating has been employed in a variety of studies in marine sediments to study environmental changes during the last 100 years (Li, 1988; Chung et al., 2004; Sanchez-Cabeza and Ruiz-Fernández, 2012). Using a manned submersible Shenhaiyongshi and a box sampler, we recovered undisturbed sediment cores for ${ }^{210} \mathrm{~Pb}$ dating from six stations in the northern SCS (Fig. 1 and Fig. S-1). The ages of five more stations were also evaluated according to $\mathrm{Li}$ (1988) (Table S-2). The sediment cores SY83 from the Xisha Trough were dated back to 1980 at
4 to $6 \mathrm{~cm}$, while the cores S03 and S04 from the nearshore stations dated back to 1980 at depth of 16 to $18 \mathrm{~cm}$ owing to their high sedimentation rates (Fig. 1 and Table S-3). The highest microplastic abundance commonly occurred at the surface sediments at all stations. Sedimentary profiles were clearly characterised by a general declining trend of microplastic abundance with an increase of depths and ages. Regression analysis was employed to estimate the pollution situation at nearshore stations over the next ten years. The 

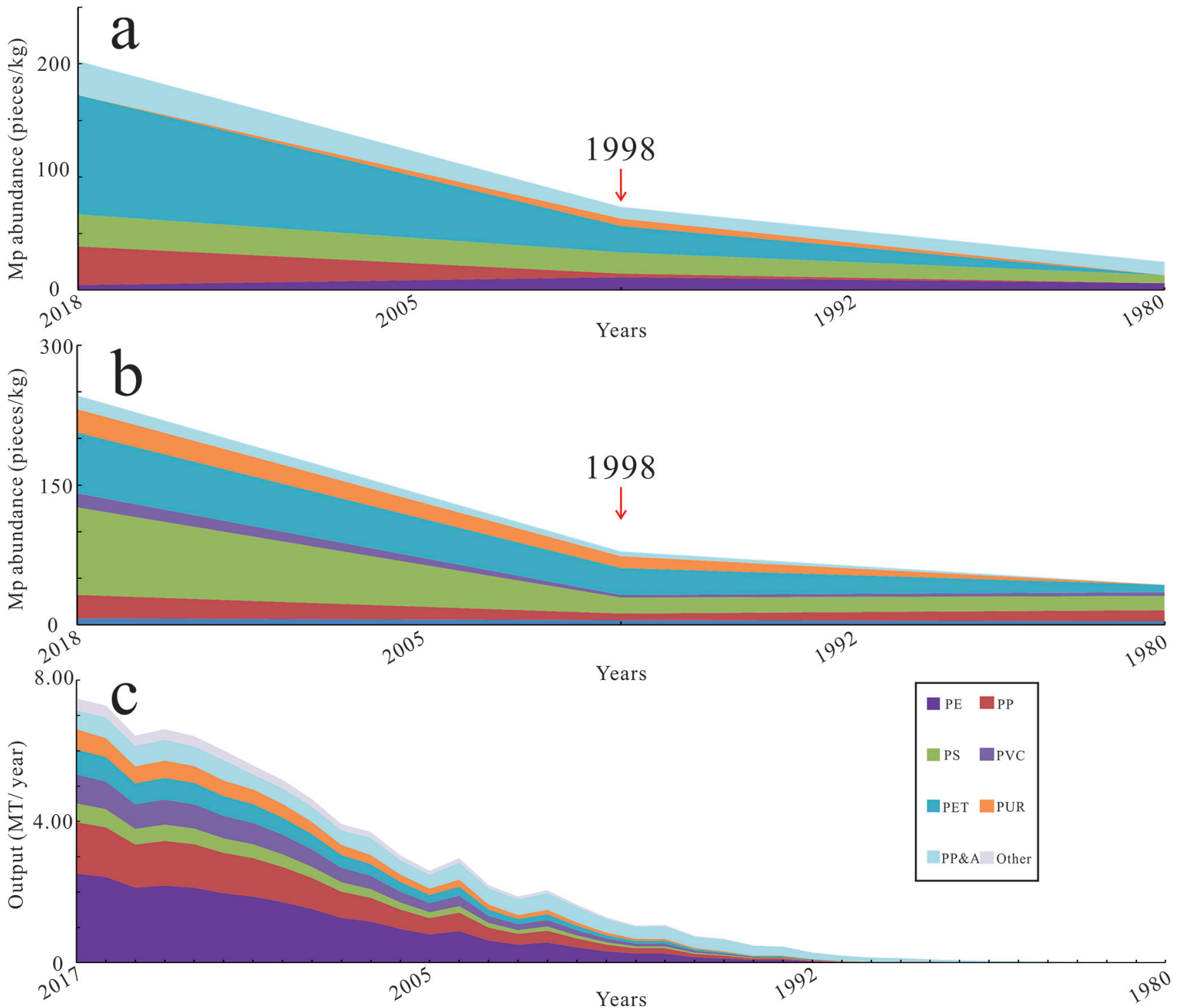

Figure 2 Microplastic abundance and composition in the northern SCS and the primary plastic output of Guangdong plastic industries. (a) Microplastic abundance and composition in Xisha Trough during 1980-2018. (b) Microplastic abundance and composition in the continental shelf during 1980-2018. (c) Output and composition of primary plastic during 1980-2017. The output data origin from the National Bureau of Statics of China, Annual Data of Guangdong Province (http://data.stats.gov.cn/easyquery.htm?cn=C01). The composition of primary plastic was calculated according to Geyer et al. (2017). PE-polyethylene, PP-polypropylene, PS-polystyrene, PVC-polyvinyl chloride, PET-polyethylene terephthalate, PUR-polyurethane, PP\&A includes polyester, polyamide, rayon and acrylic.

results estimated that the microplastic abundances would reach 848 pieces $/ \mathrm{kg}$ and 3054 pieces $/ \mathrm{kg}$ by 2028 at stations S03 and S04, nearly two times as much as those in 2018 (Fig. S-2).

Statistical analysis of the stations in Xisha Trough and the continental shelf also showed microplastic abundances dramatically increased from 1980 to 2018 (Fig. 2). In addition, the abundance of different types of microplastic exhibited an increasing trend from 1980 to 2018 as well. Intriguingly, a strong increase of microplastic abundance occurred in about 1998, representing an important breakpoint for plastic production and consumption (Fig. 2a,b). In the Guangdong province of China, plastic production growth began in the 1980s. Consequently, the output of plastic increased every year and reached 7.49 MT in 2017, which was hundreds of times higher than $0.02 \mathrm{MT}$ in 1980. The rising output of plastic in local industries is well in line with the increasing microplastic abundance in sediment cores over time. In addition to microplastic abundance, the microplastic composition varies in the sedimentary profiles at some stations (Fig. 1c), which may indicate a change in the usage of primary polymer type during different periods.

${ }^{210} \mathrm{~Pb}$ dating data were used to reconstruct the regional pollution history of microplastics in the northern SCS (Fig. 3). The results showed the variability of the contamination situation in different areas and the movement of the microplastic depocentre in different periods. During 1980-1992, microplastic abundances ranged from 0 to 169 pieces $/ \mathrm{kg}$ dry weight, with a mean abundance of 34 pieces $/ \mathrm{kg}$ dry weight. The depocentre was identified at the shelf station S04 close to the Zhujiang Delta region, at station SQW31 in the upper reaches of the Xisha Trough, and at station SY82 in the Xisha Canyon (Fig. 3b). From 1992 to 2005, microplastic abundance rose to some extent, with an average of 76 pieces $/ \mathrm{kg}$ dry weight. Although S04 still remained an active depocentre, new depocentres, SQW32 and SQW38, emerged in the middle reach of the Xisha Trough (Fig. 3c). During 2005-2018, microplastics 

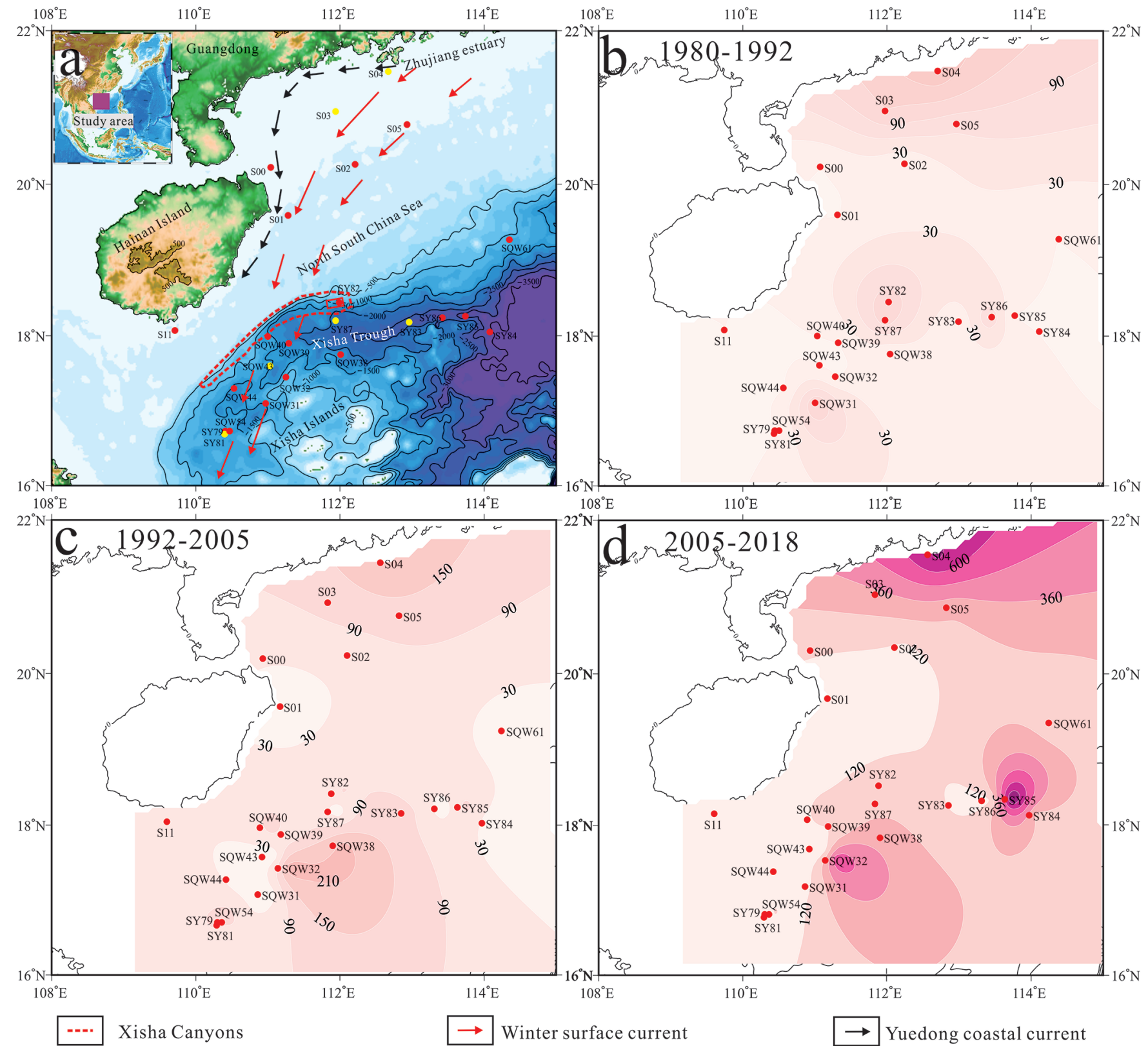

$\rightarrow$ Winter surface current

Yuedong coastal current

- Sample location $\quad{ }^{210} \mathrm{~Pb}$ date location
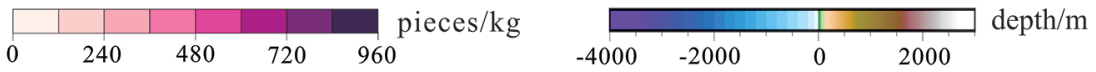

Figure 3 Contour maps of microplastic abundance (pieces $/ \mathrm{kg}$ ) in the sediments of the northern SCS. (a) The sample location of the study area (details in Table S-1). (b) Microplastic abundance in 1980-1992. (c) Microplastic abundance in 1992-2005. (d) Microplastic abundance in 2005-2018. The red rectangle in (a) shows the position of a large dump of plastics found by Peng et al. (2019). The black arrows indicate the Yuedong coastal current, while red arrows are for winter surface circulation pathways of the northern SCS that may potentially influence the transportation of microplastics in the water column of the continental shelf (Fang et al., 1998).

in the sediments increased dramatically, reaching a mean abundance of 224 pieces $/ \mathrm{kg}$ dry weight, which was about six times that in the 1980s. While S04 and SQW32 still remained as active depocentres, SY85 at the lower reach of the Xisha Trough appeared as a new depocentre (Fig. 3d). The shift of the microplastic depocentres with time, from the continental shelf to the Xisha canyon, and then to Xisha Trough, can be identified. These results provided valuable information on how the microplastic contaminated marginal sea migrated stage by stage in the past 40 years.

Since the 1980s, the nearshore station S04 in the northern SCS has continued to be a microplastic depocentre. The reason for this is that it receives a large amount of plastic debris discharge from several big rivers, such as Dongjiang, Xijiang, and Zhujiang (Cai et al., 2018). Wastewater discharge, stormwater runoff and industrial activities were possible sources of microplastics into the rivers in this area (Zhang et al., 2018). The other reason is attributed to heavy commercial fishing and shipping activities discharging a large number of plastic wastes (Peng et al., 2019; Zhang et al., 2019). Once entering the coast, a part of microplastics (in particular those with low specific density such as polypropylene and polyethylene that have been commonly identified in the whole region in this study), could be delivered by marine currents for example, the Guangdong coastal current and the winter surface current of the northern SCS, to the continental shelf. With time, these microplastics eventually settled on the seafloor of the shelf due to colonisation by organisms and the aggregation with organic debris and particles (Zarfl and Matthies, 2010; Katija et al., 2017). Once microplastics reached the seabed, they may be swept off the continental shelf by littoral drift (Paull 
et al., 2010) or bottom currents into the Xisha Canyon where a new depocentre formed. However, unlike most of the large plastic items which can be trapped in the canyon (Peng et al., 2019), microplastics might continue to be transported by the bottom current along the seabed and arrive in the low upper reach of the Xisha Trough, leading to the formation of a new depocentre in the last ten years. These results suggested that submarine canyons and troughs acted as important pathways for the transportation of microplastics from the continental shelf to the deep sea (Pham et al., 2014).

The marginal sea is an important convergence point of land-based and marine-based microplastics (Zhang et al., 2019), making it an ideal area to study the history of microplastics. Our results showed that the sediments of the marginal sea, especially the nearshore sediments, could preserve a complete record of microplastic contamination history. $\mathrm{Pb}$ isotope chronology may serve as a useful tool for reconstructing the microplastic pollution history in marginal sea sediments worldwide. In this study, we provided the first full view of the spatial and temporal variation of microplastic abundances and highlighted the situation of microplastic pollution in the northern SCS. The microplastic abundance in the SCS sediments has reached its highest level in 2018 and will likely continue to increase dramatically during the next decades if no control measures are taken. More strict laws and regulations for the usage and production of plastics are needed to be implemented to avoid further harmful microplastics entering the oceans.

\section{Acknowledgements}

We are very grateful to the pilots and crew of the R/V Tansuoyihao with manned submersible Shenhaiyongshi and R/V Zhanke 10 for their professional service during the cruises. Funding for this study was provided by the National Key Research and Development Plan of China (2016YFC0304900, 2018YFC0309802, 2017YFC0306702, 2016YFC0300503) and the National Natural Science Foundation of China (41602345).

\section{Editor: Eric H. Oelkers}

\section{Additional Information}

Supplementary Information accompanies this letter at http:// www.geochemicalperspectivesletters.org/article2012.

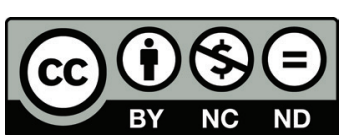

This work is distributed under the Creative Commons Attribution Non-Commercial No-Derivatives 4.0 License, which permits unrestricted distribution provided the original author and source are credited. The material may not be adapted (remixed, transformed or built upon) or used for commercial purposes without written permission from the author. Additional information is available at http://www.geochemicalperspectivesletters.org/ copyright-and-permissions.

Cite this letter as: Chen, M., Du, M., Jin, A., Chen, S., Dasgupta, S., Li, J., Xu, H., Ta, K., Peng, X. (2020) Forty-year pollution history of microplastics in the largest marginal sea of the western Pacific. Geochem. Persp. Let. 13, 42-47.

\section{References}

ANDrady, A.L., NEAL, M.A. (2009) Applications and societal benefits of plastics. Philosophical Transactions of the Royal Society B: Biological Sciences 364, 1977-1984.
Arthur, C., Baker, J., Bamford, H. (Eds.) (2009) Proceedings of the International Research Workshop on the Occurrence, Effects, and Fate of Microplastic Marine Debris. NOAA Technical Memorandum NOS-OR\&R-30.

Bergmann, M., Wirzberger, V., Krumpen, T., Lorenz, C., Primpke, S., Tekman, M.B., Gerdts, G. (2017) High Quantities of Microplastic in Arctic Deep-Sea Sediments from the HAUSGARTEN Observatory. Environmental Science \& Technology 51, 11000-11010.

CaI, M., He, H., LiU, M., Li, S., TANG, G., Wang, W., HU, J. (2018) Lost but can't be neglected: Huge quantities of small microplastics hide in the South China Sea. Science of the Total Environment 633, 1206-1216.

Chung, Y., Chang, H.C., Hung, G.W. (2004) Particulate flux and 210Pb determined on the sediment trap and core samples from the northern South China Sea. Continental Shelf Research 24, 673-691.

Claessens, M., De Meester, S., Van Landuyt, L., De Clerck, K., JANSSEN, C.R. (2011) Occurrence and distribution of microplastics in marine sediments along the Belgian coast. Marine Pollution Bulletin 62, 2199-2204

FANG, G.H., FANG, W.D., FANG, Y., WANG, K. (1998) A survey of studies on the South China Sea upper ocean circulation. Acta Oceanographica Taiwanica 37, 1-16.

LI, F.Y. (1988) Determination of recent sedimentation rates by ${ }^{210} \mathrm{~Pb}$ method in the South China Sea. Marine Sciences 3, 64-66.

Galgani, F., Souplet, A., Cadiou, Y. (1996) Accumulation of debris on the deep sea floor off the French Mediterranean coast. Marine Ecology Progress Series 142, 225-234.

Gall, S.C., Thompson, R.C. (2015) The impact of debris on marine life. Marine Pollution Bulletin 92, 170-179.

Geyer, R., JAmbeck, J.R., LaW, K.L. (2017) Production, use, and fate of all plastics ever made. Science Advances 3, doi: 10.1126/sciadv.1700782.

Goldstein, M. C., RosenberG, M., Cheng, L. (2012) Increased oceanic microplastic debris enhances oviposition in an endemic pelagic insect. Biology Letters 8, 817-820, doi: 10.1098/rsbl.2012.0298.

Hui, G., Li, S., GuO, L., Somerville, I.D., Wang, P., Wang, Q. (2019) Mechanisms of submarine canyon formation on the northern continental slope of the South China Sea. Geological Journal 54, 3389-3403.

Katija, K., Choy, C.A., Sherlock, R.E., Sherman, A.D., Robison, B.H. (2017) From the surface to the seafloor: how giant larvaceans transport microplastics into the deep sea. Science Advance 3, e1700715.

Kukulka, T., Proskurowski, G., Morét-Ferguson, S., Meyer, D.W., LAW, K. L. (2012) The effect of wind mixing on the vertical distribution of buoyant plastic debris. Geophysical Research Letters 39, L07601, doi: 10.1029/2012GL051116.

LaW, K. L., Morét-Ferguson, S., Maximenko, N.A., Proskurowski, G., Peacock, E.E., Hafner, J., Reddy, C.M. (2010) Plastic accumulation in the North Atlantic subtropical gyre. Science 329, 1185-1188.

Lebreton, L., ANDRADy, A. (2019) Future scenarios of global plastic waste generation and disposal. Palgrave Communications 5, 1-11.

Lebreton, L.C.M., Joost, V.D.Z., Damsteeg, J.W., Slat, B., Andrady, A., ReISSER, J. (2017) River plastic emissions to the world's oceans. Nature Communications 8, 15611.

LI, F. (1988) Determination of recent sedimentation rates by $210 \mathrm{~Pb}$ method in the South China Sea. Marine Sciences 3, 64-66. (In Chinese with English Abstract)

Martin, J., Lusher, A., Thompson, R.C., Morley, A. (2017) The deposition and accumulation of microplastics in marine sediments and bottom water from the Irish continental shelf. Scientific Reports 7, doi: 10.1038/ s41598-017-11079-2.

Matsuguma, Y., Takada, H., Kumata, H., Kanke, H., Sakurai, S., SuzUKI, T., ITOH, M., OKaZAKI, Y., BoOnyatumanond, R., Zakaria, M.P., WeErTS, S., NeWMAN, B. (2017) Microplastics in sediment cores from Asia and Africa as indicators of temporal trends in plastic pollution. Archives of Environmental Contamination and Toxicology $73,230-239$

Paull, C.K., Ussler III, W., Caress, D.W., Lundsten, E., Covault, J.A., Maier, K.L., XU, J., Augenstein, S. (2010) Origins of large crescent-shaped bedforms within the axial channel of Monterey Canyon, offshore California. Geosphere 6, 755-774.

Peng, X., Chen, M., Chen, S., Dasgupta, S., XU, H., TA, K., Li, J., Li, GUO, Z., BAI, S. (2018) Microplastics contaminate the deepest part of the world's ocean. Geochemical Perspectives Letters 9, 1-5.

Peng, X., Dasgupta, S., Zhong, G., Du, M., Xu, H., Chen, M., Chen, S., TA, K., LI, J. (2019) Large debris dumps in the northern South China Sea. Marine Pollution Bulletin 142, 164-168. 
Pham, C.K., Ramirez-Llodra, E., Alt, C.H.S., Amaro, T., Bergmann, M., Canals, M., Company, J.B., Davies, J., Duineveld, G., Galgani, F., Howell, K.L., Huvenne, V.A.I., Isidro, E., Jones, D.O.B., Lastras, G., Morato, T., Gomes-Pereira, J.N., Purser, A., Stewart, H., Tojeira, I., Tubau, X., Van Rooij, D., Tyler, P.A. (2014) Marine litter distribution and density in European seas, from the shelves to deep basins. PLoS One 9, doi: 10.1371/journal.pone.0095839.

Plastics Europe (2018) Plastics-The Facts 2018: An Analysis of European Plastics Production, Demand and Waste Data. Downloaded from https://www.plasticseurope.org/application/files/6315/4510/9658/Plastics_the_facts_2018_AF_web.pdf.

QIU, X., Ye, S., Wu, S., ShI, X., Zhou, D., XIA, K., FlueH, E.R. (2001) Crustal structure across the Xisha trough, northwestern South China Sea. Tectonophysics 341, 179-193.

Sanchez-CabezA, J.A., Ruiz-FernándeZ, A.C. (2012) ${ }^{210} \mathrm{~Pb}$ sediment radiochronology: an integrated formulation and classification of dating models. Geochimica et Cosmochimica Acta 82, 183-200.

SiNGH, B., SHARMA, N. (2008) Mechanistic implications of plastic degradation. Polymer Degradation and Stability 93, 561-584.

Thompson, R.C., Olsen, Y., Mitchell, R.P., Davis, A., Rowland, S.J., JoHn, A.W., Russell, A.E. (2004) Lost at sea: where is all the plastic? Science 304, 838-838.

Woodall, L.C., Sanchez-Vidal, A., Canals, M., Paterson, G.L. Coppock, R., Sleight, V., Calafat, A., Rogers, D.A., NARAYANASWAmy, E.B., ThOMPSON, R.C. (2014) The deep sea is a major sink for microplastic debris. Royal Society Open Science 1, doi: 10.1098/rsos.140317.

Zarfl, C., Matthies, M. (2010) Are marine plastic particles transport vectors for organic pollutants to the Arctic? Marine Pollution Bulletin 60, 1810-1814.

ZhANG, C., ZHOU, H., CuI, Y., WANG, C., LI, Y., ZHANG, D. (2019) Microplastics in offshore sediment in the yellow Sea and east China Sea, China. Environmental Pollution 244, 827-833.

Zhang, K., Shi, H., Peng, J., Wang, Y., Xiong, X., Wu, C., Lam, P.K. (2018) Microplastic pollution in China's inland water systems: A review of findings, methods, characteristics, effects, and management. Science of the Total Environment 630, 1641-1653. 